\title{
Danzando con Foucault
}

\author{
Dancing with Foucault
}

Manuel González de Chávez

Psiquiatra. Fundación para la Investigación y Tratamiento de la Esquizofrenia.

Correspondencia: Manuel González de Chávez (mgchavez.fundesquizofrenia@gmail.com)

Fernando COLINA (2019), Foucaultiana, Valladolid, La Revolución Delirante. ISBN: 978-84-09-15418-0, 145 páginas.

$\mathrm{F}$

ERNANDO COLINA ES, SIN DUdA, UNO DE lOS PSIQUiATRAS más cultos e inteligentes de nuestra generación, con una extraordinaria lucidez y un dominio elegante y bello de la lengua castellana difícil de igualar. Su último libro, Foucaultiana, es una muestra más de sus muchos conocimientos y de su habilidad para exponerlos con acierto y claridad.

En Foucaultiana, elige tres temas de la obra de Michel Foucault que le son especialmente próximos — la locura, la sexualidad y la subjetividad — y baila con ellos tres bellas danzas barrocas con la misma secuencia de movimientos: las ideas y los efectos. Primero, expone la obra de Foucault sobre el tema, luego dialoga con ese aspecto del pensamiento foucaultiano y, finalmente, como treinta y cinco ańos después de la muerte de Foucault esos temas han evolucionado históricamente, Fernando Colina los actualiza y expone su propia opinión sobre ellos con un gran nivel, a la altura de su elegido interlocutor.

Y sintetizar el pensamiento de Foucault en estos temas claves como lo hace no es nada fácil, porque Foucault no fue lineal y continuista en su pensamiento, sino que muchas veces fue contradictorio, avanzaba desdiciéndose de escritos anteriores y, además, presumía de ello. Y porque también su pensamiento se dispersa muchas veces a lo largo de los años entre libros, cursos, conferencias, entrevistas y escritos varios, sin contar lo que va a suponer su obra póstuma. Dijo que no quería que se 
publicasen sus textos inéditos y rompió algunos de ellos, pero conservó bajo custodia de los bancos unas 117 cajas con 37.000 páginas y escritos que fueron adquiridas después por la Bibliothèque Nationale y seguramente se publicarán poco a poco en los próximos años.

Además, los temas de la locura y la sexualidad están tremendamente enraizados a la misma biografía de Foucault. Ya mucho antes de escribir y publicar su tesis sobre la Historia de la locura en la época clásica, siguió tratamiento psiquiátrico, aconsejado por su padre, con Jean Delay, uno de los grandes popes de la psiquiatría francesa y un pionero de la naciente psicofarmacología, al que le unió siempre una gran amistad, y luego hizo un par de intentos de psicoanalizarse que abandonó pronto porque, según él, se aburría con el análisis. También frecuentó mucho el Hospital Sainte-Anne, unas veces como psicólogo investigador y muchas más como asistente a las sesiones clínicas del Servicio de Psiquiatría, que en los años cincuenta fueron uno de los acontecimientos preferidos de algunas élites intelectuales parisinas. También la sexualidad y su extensa historia es muy relevante en la obra de Foucault, como lo fue en su vida, con la evolución de una homosexualidad adolescente vergonzante y conflictiva a una defensa valiente y pública de la misma como la forma superior de la vida sexual, al sadomasoquismo como la creación de nuevas posibilidades de placer y a una sexualidad de alto riesgo, que le hizo una de las primeras víctimas del síndrome de inmunodeficiencia adquirida y le llevó a una muerte temprana con cincuenta y ocho años.

Es admirable cómo en este libro Colina nos expone con fluidez el pensamiento de Foucault respecto a la locura, la sexualidad y la subjetividad, algo que no debería extrañarnos después de haber leído lo accesible que hace la psicopatología a los estudiantes en su Manual de psicopatología con Laura Martín. Y cómo en el diálogo que establece con la obra de Foucault es a veces difícil saber dónde termina Foucault y dónde empieza Colina. Pero ya en la tercera parte de cada capítulo se suelta de la mano de Foucault y es Colina mismo quien nos habla de la locura, la sexualidad y la subjetividad. Y lo hace con la lucidez que le caracteriza. Nos habla de los activismos críticos y disidentes de la psiquiatría, la hipertrofia del discurso del etiquetado del diagnóstico, la salud mental inclusiva, las formas de dominación en las prácticas curativas de la psiquiatría actual y los intentos de normalización y domesticación de la locura. Con mucha más extensión reflexiona sobre los cambios de la sexualidad en los años más recientes, tanto en las perversiones como en las posibles elecciones sexuales y en todas las variaciones actuales de la identidad sexual. Finalmente, en el último capítulo de este pequeño libro, Colina hace también consideraciones muy atinadas sobre la evolución histórica de la identidad y la subjetividad. En definitiva, un lujo de libro. 